\title{
An 8-year retrospective study of adult and paediatric Burkitt's lymphoma at Tygerberg Hospital, South Africa
}

\begin{tabular}{|c|c|}
\hline \multicolumn{2}{|c|}{$\begin{array}{l}\text { Authors: } \\
\text { Ernest Musekwa }{ }^{1,2} \\
\text { Zivanai C. Chapanduka } \\
\text { Fatima Bassa }{ }^{3} \text { (1) } \\
\text { Mariana Kruger }\end{array}$} \\
\hline \multicolumn{2}{|c|}{$\begin{array}{l}\text { Affiliations: } \\
{ }^{1} \text { Division of Haematology, } \\
\text { Department of Pathology, } \\
\text { Faculty of Medicine and } \\
\text { Health Sciences, Stellenbosch } \\
\text { University, Cape Town, } \\
\text { South Africa }\end{array}$} \\
\hline \multicolumn{2}{|c|}{$\begin{array}{l}{ }^{2} \text { National Health Laboratory } \\
\text { Service, Cape Town, } \\
\text { South Africa }\end{array}$} \\
\hline \multicolumn{2}{|c|}{$\begin{array}{l}{ }^{3} \text { Division of Clinical } \\
\text { Haematology, Department } \\
\text { of Medicine, Faculty of } \\
\text { Medicine and Health } \\
\text { Sciences, Stellenbosch } \\
\text { University, Cape Town, } \\
\text { South Africa }\end{array}$} \\
\hline \multicolumn{2}{|c|}{$\begin{array}{l}{ }^{4} \text { Paediatric Oncology Unit, } \\
\text { Department of Paediatrics } \\
\text { and Child Health, Faculty } \\
\text { of Medicine and Health } \\
\text { Sciences, Stellenbosch } \\
\text { University, Cape Town, } \\
\text { South Africa }\end{array}$} \\
\hline \multicolumn{2}{|c|}{$\begin{array}{l}\text { Corresponding author: } \\
\text { Mariana Kruger, } \\
\text { marianakruger@sun.ac.za }\end{array}$} \\
\hline \multicolumn{2}{|c|}{$\begin{array}{l}\text { Dates: } \\
\text { Received: } 19 \text { July } 2019 \\
\text { Accepted: } 21 \text { Feb. } 2020 \\
\text { Published: } 30 \text { Apr. } 2020\end{array}$} \\
\hline \multicolumn{2}{|l|}{ Read online: } \\
\hline 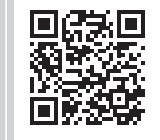 & $\begin{array}{l}\text { Scan this QR } \\
\text { code with your } \\
\text { smart phone or } \\
\text { mobile device } \\
\text { to read online. }\end{array}$ \\
\hline
\end{tabular}

Background: Burkitt lymphoma(BL) is a high grade non-Hodgkin lymphoma, which may be underdiagnosed in South Africa, due to a high burden of infectious diseases such as HIV and TB which may present with similar clinical features.

Aim: To describe demographics and clinico-pathological characteristics of patients diagnosed with BL.

Setting: Tygerberg Hospital (TBH), South Africa between 2007-2014.

Methods: We performed a retrospective descriptive and survival analysis of patients diagnosed with BL at TBH between 01 January 2007 and 31 December 2014 with at least 24-month followup. Data was collected from the Tygerberg Lymphoma Study Group database and the South African Children Cancer Study Group Tumour Registry.

Results: There were 73 patients with BL, of whom 68 were admitted to TBH and whose data was further analysed. The majority of patients were adults (74\%). There was a female predominance in adults and a male predominance in children $(p=0.002)$. Various regimens were used in adults while a single treatment protocol was used in children. The proportion of patients with HIV and advanced BL was higher in adults than in children. The 2-year overall survival of the treatment group was $45 \%$. The outcome of patients with BL in adults (34\%) was poorer than that of children $(69 \%)(p=0.022)$. HIV negative patients had a non-significant survival advantage $(57 \%)$ over HIV positive patients with $41 \%$ 2-year overall survival ( $p=0.2876)$.

Conclusion: This study demonstrates a better cure rate in children treated for BL compared to adults, with HIV-infection being a risk factor for poor outcome.

Keywords: epidemiology; Burkitt lymphoma; human immunodeficiency virus; tuberculosis; children; adults; treatment; outcome; South Africa.

\section{Introduction}

Burkitt's lymphoma (BL) was first described in Eastern Africa, initially as sarcoma of the jaw, but later identified as a form of non-Hodgkin's lymphoma. ${ }^{1}$ A diagnosis of BL is made if the bone marrow is involved. ${ }^{2}$ The disease becomes rapidly fatal if left untreated. ${ }^{3}$ With the development of intensive chemotherapy treatment protocols, the long-term survival has dramatically improved..$^{4,5}$

Burkitt's lymphoma accounts for more than $50 \%$ of all childhood cancers in endemic areas and for $40 \%-50 \%$ of childhood non-Hodgkin's lymphomas (NHLs) in non-endemic areas such as North America and Western Europe. ${ }^{6}$

Before the era of highly active anti-retroviral therapy (HAART), the incidence of BL was estimated to be 1000 times higher in human immunodeficiency virus (HIV)-positive patients than in the general population. ${ }^{7}$ More male patients are affected, with a male to female ratio ranging from 2:1 to 3:1 reported amongst HIV-negative patients in American BL studies. ${ }^{8,9}$

The World Health Organization (WHO) Classification of Tumours of Haematopoietic and Lymphoid Tissues (revised 4th edition) divides BL into three clinical variants. ${ }^{10,11}$ The endemic variant is primarily found in African children aged 4-7 years and is twice more common in boys than in girls. ${ }^{12}$ The sporadic variant occurs worldwide. Immunodeficiency-associated BL can also

How to cite this article: Musekwa E, Chapanduka ZC, Bassa F, Kruger M. An 8-year retrospective study of adult and paediatric Burkitt's lymphoma at Tygerberg Hospital, South Africa. S. Afr. j. oncol. 2020;4(0), a93. https://doi.org/10.4102/sajo.v4i0.93

Copyright: ( 2020 . The Authors. Licensee: AOSIS. This work is licensed under the Creative Commons Attribution License. 
occur in patients with congenital or acquired immunodeficiency disorders or in organ transplant patients receiving immunosuppressive drugs. ${ }^{13}$

Burkitt's lymphoma has three chromosomal translocations, namely $t(8 ; 14)(\mathrm{q} 24 ; \mathrm{q} 32)$ or its variants $t(2 ; 8)$ and $t(8 ; 22)$, involving myc oncogene at $8 \mathrm{q} 24$ with one of the immunoglobulin (Ig) loci partners such as IgHeavy at $14 q 32$ or IgKappa at 2 p12 or IgLambda at 22q11. ${ }^{14}$

The WHO 2016 classification has added a new provisional entity designated 'Burkitt-like lymphoma with $11 \mathrm{q}$ aberration'. This new entity has more complex karyotypes, lower levels of myc expression and a degree of morphological pleomorphism. ${ }^{15}$

The clinical symptoms depend on the clinical variant of BL. ${ }^{16}$ The endemic variant usually involves the jaw or other facial bones, ${ }^{1}$ but can affect the gastrointestinal tract, ovaries, breasts and the central nervous system where it causes nerve damage resulting in weakness and paralysis. ${ }^{10,16}$ The sporadic and immunodeficiency-associated variants involve mainly the bowel, forming bulky abdominal tumour masses and massive hepatosplenomegaly. Bone marrow infiltration also occurs. Several staging systems are used, including the St. Jude/Murphy staging and Ann Arbor staging systems.

The introduction of intensive multi-agent chemotherapy resulted in improved outcomes in paediatric BL but also increased treatment toxicity in adults, especially the elderly. ${ }^{17}$ Surgical de-bulking is no longer recommended. ${ }^{18}$ The standard treatment of $\mathrm{BL}$ is intensive multi-agent chemotherapy combined with good supportive care. ${ }^{19}$

Early intensive chemotherapy will usually cure BL in the majority of children, leading to long-term survival rates of up to $90 \%,{ }^{20}$ depending on the treatment protocol and supportive care. ${ }^{21}$ The results are variable for adults..$^{22,23,24,25}$ Cure is also achieved in lower middle-income countries (LMICs) with modified treatment protocols. ${ }^{26}$

For Adults diagnosed with BL, the different protocols have been used based on risk stratification, namely LMB regimen (Course 1 COP: cyclophosphamide, vincristine, prednisone and intrathecal methotrexate; Course 2 COPAD 1: cyclophosphamide, vincristine, prednisone, doxorubicin and intrathecal methotrexate; Course 3 COPAD 2: cyclophosphamide, vincristine, prednisone, doxorubicin and intrathecalmethotrexate;Course 4CVM1:cyclophosphamide, vincristine, methotrexate and intrathecal methotrexate; Course 5 CVM 1: cyclophosphamide, vincristine, methotrexate and intrathecal methotrexate); HyperCVAD regimen (Course A consists of cyclophosphamide, vincristine, doxorubicin [adriamycin], dexamethasone, cytarabine, mesna and methotrexate; Course B consists of methotrexate, leucovorin, sodium bicarbonate and cytarabine); CODOX-M with or without alternating IVAC regimen (CODOX-M regimen is as follows: cyclophosphamide, doxorubicin, vincristine, leucovorin rescue, intrathecal cytarabine and intrathecal methotrexate, while IVAC regimen is as follows: ifosfamide with mesna protection, etoposide, cytarabine and intrathecal methotrexate); CALGB (cancer and leukaemia group B) 9251 regimen (Course I consists of cyclophosphamide and prednisone; Courses II, IV, and VI comprise the following: ifosfamide, mesna, methotrexate, leucovorin, vincristine, cytarabine, etoposide and dexamethasone; Courses III, V, and VII comprise the following: cyclophosphamide, methotrexate, leucovorin, vincristine, adriamycin and dexamethasone; intrathecal chemotherapy consists of methotrexate plus cytarabine all administered on day 1 of each course [II-VII]); DA-EPOCH-R regimen (dose-adjusted etoposide, prednisolone, vincristine, cyclophosphamide, doxorubicin and rituximab); MACOP-B regimen (methotrexate, adriamycin, cyclophosphamide, vincristine, prednisone and bleomycin); CHOP regimen (cyclophosphamide, vincristine, doxorubicin and prednisone) and CHOEP regimen (cyclophosphamide, vincristine, doxorubicin, etoposide and prednisone). ${ }^{6,10,16,17,25,26,27}$

For children, the French-American-British/LMB 1996 (FAB/ LMB-96) international study protocols currently achieve $90 \%$ cure for localised unresected disease. Even in high-risk BL, up to $90 \%$ cure rates have been reported..$^{19,22}$

Multi-drug salvage regimens may be used in refractory disease $^{28}$ and transplant options may be offered, ${ }^{27}$ but outcomes are variable and nowhere near as good as in the first-line response. Cyclophosphamide (CPM) is found to be an affordable chemotherapy for endemic BL in LMICs. ${ }^{26}$

Human immunodeficiency virus infection may mimic tuberculosis (TB) and/or BL. The socio-economic burden of multi-drug resistance TB (MDR-TB) on patients in LMICs is reported to be high. ${ }^{29}$ Therefore, undiagnosed BL or delayed diagnosis of $\mathrm{BL}$ in patients with $\mathrm{HIV}$ and/or acquired immunodeficiency syndrome (HIV and/or AIDS) and/or complicated TB may lead to depression, stigma, discrimination, psychological distress and financial hardship. ${ }^{30,31}$

South African HIV treatment roll-out started in 2004. Highly active anti-retroviral therapy was used from 2004 to 2012 and combined antiretroviral therapy (cART) was introduced in 2013. This followed the National Guidelines for Management of HIV and was updated by the South African HIV Clinicians Society. This resulted in starting ART in all patients diagnosed with HIV infection regardless of the CD4 count or symptoms. ${ }^{32}$

South Africa has unique health and socio-economic challenges, similar to the rest of upper middle income countries (MIC) as defined by the World Bank's analytical income classification 2014.

This study aims to document the number of patients with BL, to determine the treatment protocol used and patient outcomes and to compare patient outcomes between adults and children, as well as between HIV-infected and non-HIVinfected patients with BL, diagnosed at Tygerberg Hospital (TBH), South Africa, between 2007 and 2014. ${ }^{33}$ 


\section{Patients and methods}

The study was conducted at TBH, the second largest hospital in the country and a referral tertiary care institution for approximately half of the population of Western Cape province. ${ }^{33}$ We conducted a retrospective analysis of patients, diagnosed with BLat TBH from 01 January 2007 to 31 December 2014 with 2-year follow-up. All children and adults who were only diagnosed with BL or Burkitt leukaemia at TBH were included. Patients were excluded if the diagnosis of BL could not be confirmed and if patients were referred from other hospitals after having already been diagnosed with BL.

Case ascertainment and clinical information were derived from the Tygerberg Lymphoma Study Group (TLSG) database, Stellenbosch University. Paediatric data were obtained from the South African Children Cancer Study Group (SACCSG) Tumour Registry for all children treated at TBH. The National Health Laboratory Services (NHLS) electronic database supplemented the TBH clinical records.

Data collection included demographic data (date of birth, age at diagnosis and sex), stage as per St Jude modification of Ann Arbor staging system or LMB staging, NHLS risk stratification, comorbid disease, treatment protocol and outcome. ${ }^{34}$

The diagnosis was made according to the WHO Classification of Tumours of Haematopoietic and Lymphoid Tissues 2017 criteria for BL (revised 4th edition). ${ }^{11,16}$

Data collected included initial clinical assessments, histology, bone marrow biopsy, cerebrospinal fluid cytopathology, computerised tomography of the chest and/ or abdomen and/or pelvis and/or brain if clinically indicated. Positron emission tomography/computed tomography (PET/CT) scan was rarely used in children but commonly used in adults. Leukaemic presentation of BL was defined by predominance of bone marrow or peripheral blood (> 25\% blasts) involvement in the absence of significant nodal disease.

The treatment protocol used in children's group was theLMB-96, ${ }^{34,35}$ whereas different regimens were used in adult group, namely LMB-96, hyper-CVAD, Stanford $\mathrm{V}$ and methotrexate with leucovorin, doxorubicin, cyclophosphamide, vincristine, prednisone and bleomycin (MACOP-B). ${ }^{10,27,34,35,36,37}$ The later regimen (i.e. MACOP-B) was used in patients who had a poor performance status and/or in the elderly. ${ }^{38}$ All HIV-infected patients received ART: all children and adults from 2013 onwards. ${ }^{39}$

Statistical analysis of all data was performed using Microsoft Excel ${ }^{\circledR}$ and the Statistical Software Package SPSS ${ }^{\circledR}$ v 24. Results were summarised and presented by year, sex and HIV status using descriptive statistical methods. $p$-values were obtained using Pearson's chi-square and one-sided Fisher's exact calculation methods, in which a value of $<0.05$ indicates statistical significance.
A waiver of individual patient consent was obtained. The custodians of the databanks provided consent for the retrospective data collection and analysis. All data were analysed anonymously using the unique study number to ensure protection of the patient privacy.

\section{Ethical considerations}

Ethical approval to conduct the study was obtained from the Health Research Ethics Committee, Stellenbosch University (Reference number: S17/03/046), which complied with the principles of the Declaration of Helsinki, 2013.

\section{Results}

There were 73 patients initially identified with a diagnosis of BL. Five adult patients (7\%) were excluded from further analysis as only diagnostic specimens were available (see Figure 1).

Sixty-eight (100\%) patients were analysed, of whom 50 $(73.5 \%)$ were adults and $18(26.5 \%)$ were children, with a median age of 36 years (range $=2-69$ years; interquartile range $(\mathrm{IQR})=43-10)$. Children had a median age of 5.5 years (range $=2-12$ years; IQR $=8-3$ ), whilst adults had a median age of 37 years (range $=18-69$ years; $\mathrm{IQR}=42-30.5)$. Overall, 39 patients $(74 \%)$ were female patients and 29 were male patients, with male to female ratio of 1:1.3; but this was 3:1 for children and 1.2:1 for adults, respectively $(p=0.002)$.

A lymph node biopsy confirmed the diagnosis of BL in 59 patients $(87 \%)$, whilst nine patients $(13 \%)$ presented with Burkitt leukaemia, without nodal involvement, including one child. Thirty-four patients (50\%) presented with pelvic and abdominal involvement, whilst 23 patients $(34 \%)$ presented with facial and neck involvement. One patient presented with breast involvement. One patient presented with extramedullary thoracic (T8-T11) mass.

Forty-seven patients presented with an advanced stage disease (III-IV), whilst 21 patients had limited disease (I-II). More than half of the children presented with limited disease, whilst the majority of patients in the adult group were diagnosed with advanced disease ( $p=$ 0.008). Fifty-three patients were HIV-positive, most of whom where adults $(p=0.00001)$ (see Table 1$)$. The mean CD4 counts was 250 cells per $\mu \mathrm{L}$ (range $=11-832$ cells per $\mu \mathrm{L} ;$ median $=198$ cells per $\mu \mathrm{L})$. HIV viral load results were available in 18 patients, and only five (11\%) adults were virally suppressed at diagnosis (see Table 2 ). There were six patients with pulmonary $\mathrm{TB}$ at diagnosis, of whom two were children and four adults.

Seventeen patients (25\%), namely two children and 15 adults, died prior to the initiation of chemotherapy (see Figure 1). Three patients $(18 \%)$ had limited stage disease, whilst 14 patients presented with an advanced disease. Causes of 


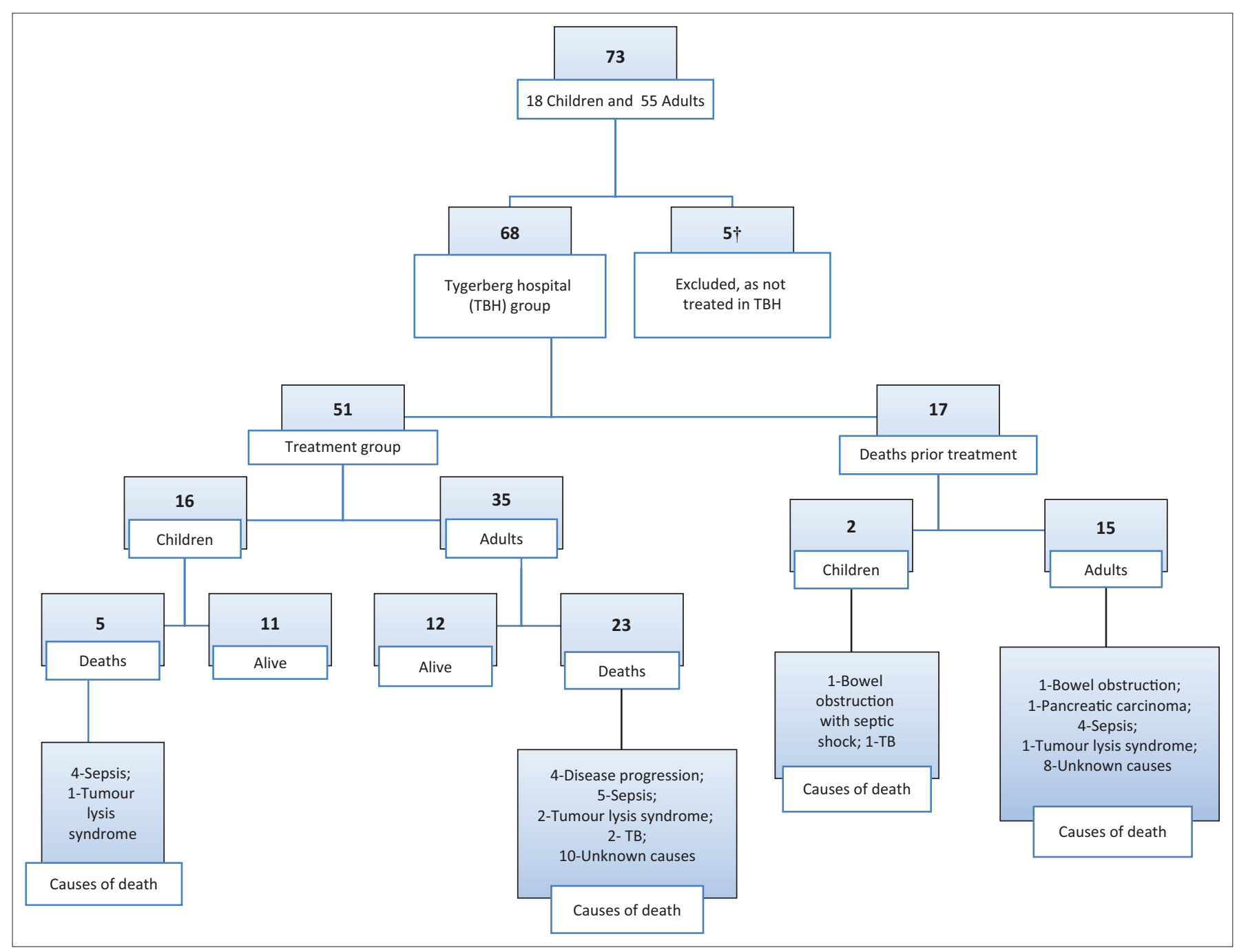

$\dagger$, Five patients were excluded from further analysis as only diagnostic specimens were available as the patients were treated outside Tygerberg Hospital. FIGURE 1: Schematic outline of Burkitt lymphoma study.

death in the two children were bowel perforation with septic shock in one patient and complicated TB in other child. All 15 of the adults deaths had HIV, and causes of death (see Figure 1) were as follows: one died of sepsis; one had confirmed Klebsiella pneumonia; one patient had TB with confirmed Klebsiella pneumoniae plus methicillin-resistant Staphylococcus aureus and TB; one patient had Guillain-Barre syndrome with confirmed Acinetobacter baumannii; one patient had disseminated TB; one patient had concomitant pancreatic head carcinoma; one patient died of bowel obstruction with bilateral hydronephrosis and eight patients had unknown death causes.

The 2-year overall survival (OS) for the total treated cohort was $45 \%(n=23)$. The children had an OS of $69 \%$ versus adults with an OS of $36 \%$, which was statistically significant $(p=0.022)$ (Table 1$)$. The majority of the survivors $(52 \%)$ had limited disease. Only one of the surviving patients presented with Burkitt leukaemia and two-thirds (65\%) of the survivors had concomitant HIV infection. Treatment protocols were the LMB 96 protocol $(n=29)$ and various
non-LMB-96 protocols $(n=22)$ (see Table 2). All children $(n=16 ; 100 \%)$ and 13 adults received treatment according to the LMB-96 protocol, whilst 22 adults (66\%) received nonLMB-96 protocols. Of the 11 surviving children, treated with the LMB-96 regimen, eight presented with limited disease, whilst four had concomitant HIV infection. Four surviving adults were treated with the LMB-96 regimen, of whom three presented with advanced disease, whilst all had concomitant HIV infection.

The various non-LMB-96 protocols comprised of hyperCVAD $(n=11 ; 50 \%)$, Stanford V $(n=8 ; 36 \%)$ and MACOP-B $(n=3 ; 14 \%)$ (see Table 3$)$. The eight surviving adults presented with advanced disease and seven of eight had concomitant HIV infection. Three patients received hyperCVAD regimen, three received Stanford $V$ regimen and two received MACOP-B regimen. The 2-year OS of the patients $(n=8)$ in the non-LMB-96 protocol was $36 \%$. Stanford V and MACOP-B regimens had better survival compared to LMB-96 and hyper-CVAD regimens (OS: 45\% vs. $32 \%$; $p=0.442$ ), but this was not statistically significant and sample size was too small. 
TABLE 1: Epidemiological characteristics.

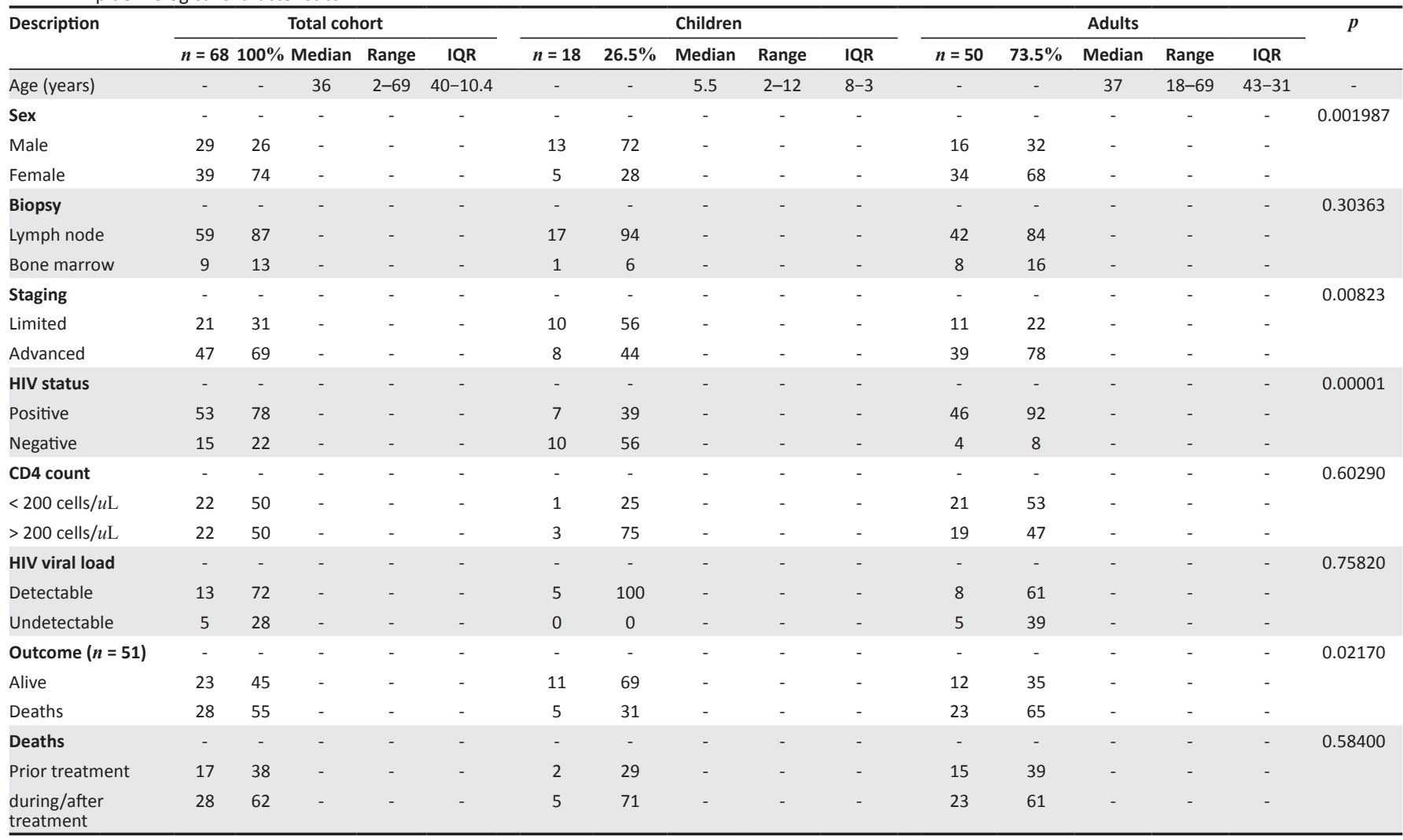

TABLE 2: Human immunodeficiency virus status of human immunodeficiency virus-infected patients.

\begin{tabular}{|c|c|c|c|c|c|c|}
\hline \multirow[t]{2}{*}{ Description } & \multicolumn{2}{|c|}{ Total cohort $(n=53)$} & \multicolumn{2}{|c|}{ Children $(n=7)$} & \multicolumn{2}{|c|}{ Adult $(n=46)$} \\
\hline & $n$ & $\%$ & $n$ & $\%$ & $n$ & $\%$ \\
\hline \multicolumn{7}{|l|}{ CD4 count } \\
\hline$>200$ cells/uL & 21 & 40 & 2 & 29 & 19 & 41 \\
\hline$<200$ cells/uL & 23 & 43 & 2 & 29 & 21 & 46 \\
\hline Unknown & 9 & 17 & 3 & 42 & 6 & 13 \\
\hline \multicolumn{7}{|l|}{ Viral load } \\
\hline Undetectable & 5 & 9 & 0 & 0 & 5 & 11 \\
\hline Detectable & 13 & 25 & 5 & 71 & 8 & 17 \\
\hline Unknown & 35 & 66 & 2 & 29 & 33 & 72 \\
\hline
\end{tabular}

TABLE 3: Outcome by treatment protocol.

\begin{tabular}{|c|c|c|c|c|c|}
\hline \multirow[t]{2}{*}{ Outcome } & \multirow{2}{*}{$\begin{array}{c}\text { Total } \\
(n=51)\end{array}$} & \multicolumn{2}{|c|}{ Children $(n=16)$} & \multicolumn{2}{|c|}{ Adults $(n=35)$} \\
\hline & & Alive $(n=11)$ & Dead $(n=5)$ & Alive $(n=12)$ & Dead $(n=23)$ \\
\hline LMB 96 & 29 & 11 & 5 & 4 & 9 \\
\hline Hyper-CVAD & 11 & 0 & 0 & 3 & 8 \\
\hline Stanford V & 8 & 0 & 0 & 3 & 5 \\
\hline MACOP-B & 3 & 0 & 0 & 2 & 1 \\
\hline
\end{tabular}

MACOP-B, methotrexate, bleomycin, adriamycin, cyclophosphamide, vincristine, dexamethasone; hyper CVAD, hyperfractionated cyclophosphamide, vincristine, cytarabine, doxorubicin.

Twenty-eight patients died during treatment (see Figure 1). Two adults and one child died of tumour lysis syndrome after receiving debulking chemotherapy. The deaths of children, who died during treatment were as follows: one child (HIV negative) died of septic shock; one child (HIV positive) died of confirmed Klebsiella pneumoniae infection; one child (HIV negative) died of neutropenic sepsis; one child (HIV positive) died of confirmed Acinetobacter baumannii infection with TB and one child (HIV negative) died because of renal failure secondary to tumor lysis syndrome (TLS) (as mentioned above during debulking therapy). The adult deaths during treatment were as follows: four died because of disease progression; five died of sepsis; two died of tumour lysis syndrome after receiving debulking chemotherapy (as mentioned above during debulking therapy); two died because of TB and 10 because of unknown death causes. The causes of death amongst the adults in the LMB-96 regimen were as follows: two died of tumour lysis syndrome after debulking (as mentioned above); one died of sepsis with confirmed coagulase-negative Staphylococcus and Acinetobacter baumanni infection; one died of pulmonary TB; two died of disease progression and three had unknown death causes.

The OS was better in the HIV-negative $(57 \%)$ patients than HIV-positive $(41 \%)$ patients, although the difference was not statistically significant $(p=0.287)$ (see Table 4$)$. Seven surviving children were HIV negative, whilst four had concomitant HIV infection. Two children, who died had concomitant HIV infection. There was no obvious association between OS and HIV status in children $(p=0.676)$ (see Table 5).

Of the 12 surviving adults, 11 had concomitant HIV infection, whilst only one was HIV negative (see Table 6). Of the 23 adults who died, 20 had concomitant HIV infection, whilst three were HIV negative. In some patients with known HIV diagnosis, the records of CD4 and HIV viral load were not available in the NHLS database, suggesting compliance problem, and therefore, it was difficult to ascertain the therapy records from local clinic. 
TABLE 4: Outcome by human immunodeficiency virus (HIV) status in treatment group.

\begin{tabular}{|c|c|c|c|c|c|c|c|}
\hline \multirow[t]{2}{*}{ Outcome } & \multicolumn{2}{|c|}{ Total $(n=51)$} & \multicolumn{2}{|c|}{ Dead $(n=28)$} & \multicolumn{2}{|c|}{ Alive $(n=23)$} & \multirow[t]{2}{*}{$p$} \\
\hline & $n$ & $\%$ & $n$ & $\%$ & $n$ & $\%$ & \\
\hline Positive & 37 & 73 & 22 & 79 & 15 & 65 & 0.287 \\
\hline Negative & 14 & 27 & 6 & 21 & 8 & 35 & \\
\hline
\end{tabular}

TABLE 5: Outcome by human immunodeficiency virus (HIV) status in children

\begin{tabular}{|c|c|c|c|c|c|c|c|}
\hline \multirow[t]{2}{*}{ Outcome } & \multicolumn{2}{|c|}{ Total $(n=16)$} & \multicolumn{2}{|c|}{ Dead $(n=5)$} & \multicolumn{2}{|c|}{ Alive $(n=11)$} & \multirow[t]{2}{*}{$p$} \\
\hline & $n$ & $\%$ & $n$ & $\%$ & $n$ & $\%$ & \\
\hline Positive & 6 & 37 & 2 & 40 & 4 & 64 & 0.899 \\
\hline Negative & 10 & 63 & 3 & 60 & 7 & 36 & \\
\hline
\end{tabular}

TABLE 6: Outcome by human immunodeficiency virus (HIV) status in adults.

\begin{tabular}{|c|c|c|c|c|c|c|c|}
\hline \multirow[t]{2}{*}{ Outcome } & \multicolumn{2}{|c|}{ Total $(n=35)$} & \multicolumn{2}{|c|}{ Dead $(n=23)$} & \multicolumn{2}{|c|}{ Alive $(n=12)$} & \multirow[t]{2}{*}{$p$} \\
\hline & $n$ & $\%$ & $n$ & $\%$ & $n$ & $\%$ & \\
\hline Positive & 31 & 89 & 20 & 87 & 11 & 92 & 0.677 \\
\hline Negative & 4 & 11 & 3 & 13 & 1 & 8 & \\
\hline
\end{tabular}

Human immunodeficiency virus therapy information was not available at the time of diagnosis, and the treatment was initiated as soon as the diagnosis of HIV was confirmed.

The six patients with TB infection had concomitant HIV infection, whilst only one presented with limited disease. Of the four adults who had TB, two died prior to initiation of treatment, whilst two died during treatment. Of the two children who had TB, one died prior to initiation of treatment whilst one died during treatment.

\section{Discussion}

Burkitt's lymphoma is the third most common paediatric lymphoma in South Africa according to South African Children's Tumour Registry and the commonest HIV-related lymphoma (HRL) seen in adult population followed by diffuse large B-cell lymphoma subtypes as reported by TLSG (2002-2009). ${ }^{40,41}$ In the Western Cape province, sporadic BL (61\%) was more common in children and immunodeficiency-associated BL (93\%) predominated in the adult population, which is demonstrated in this singlecentre study. ${ }^{41}$ In non-endemic areas, BL accounts 40\%-50\% of childhood NHLs. ${ }^{6}$ In the United States, BL comprises 30\% of paediatric lymphomas and $<1 \%$ of adult NHLs. ${ }^{42}$

The peak incidence was in the three to eight age groups for children and in the 31-43 age groups for adults. The male to female ratio was higher in the children as compared to adults ( $3: 1$ vs. $1: 2.2 ; p=0.002$ ). The study conducted in Southern and Eastern Europe showed peak age of $5-9$ years, ${ }^{43}$ whilst the American study reported 4-7 years peak age in sporadic BL variant with male to female ratio of $2: 1.8^{44}$ and similar patterns are seen in African studies. ${ }^{45}$ The predominance of women infected by HIV reflects the South Africa national demographics of HIV prevalence ${ }^{46}$ and is comparable to other South African ${ }^{47,48}$ and international studies. ${ }^{49}$

A predominance of presentation in abdominal and pelvic sites rather than in the jaw distinguishes this study of
South African patients from those reported from endemic regions in Africa. ${ }^{8,24}$ Breast tissue involvement was rarely seen in our study. ${ }^{24}$ Leukemic presentation of BL in the absence of a tissue involvement (pure Burkitt leukaemia) is very rare. This study identified nine patients with pure Burkitt leukaemia. One HIV-positive adult, with Burkitt leukaemia achieved complete remission. ${ }^{2}$

The sporadic form and limited disease (stages I and II) predominated $(56 \%)$ in children, whilst immunodeficiencyassociated variant and advanced disease predominated $(78 \%)$ in adults $(p=0.008)$ with the latter showing poorer outcome. Similar patterns were observed in the United States, in which a multi-variable analysis found that younger age was associated with lower mortality, whilst older age, black race and advanced stage were associated with higher mortality. ${ }^{50} \mathrm{~A}$ Brazilian study reported complete remission in 38 children (84.4\%) with 35 months followup. ${ }^{51}$ In contrast to our findings, a French study observed a 2-year survival rate of $70 \%$ in a large prospective series of 72 adult BL patients treated with the French adapted paediatric LMB protocol base. ${ }^{26}$

The average age (37 years) and median CD4 count (198 cells per $\mathrm{uL}$ ) are similar to other studies of adult HIV-associated BL. ${ }^{49,52}$ Poor prognostic factors in adult HIV patients are similar to our study, namely CD4 count $<200$, opportunistic infection (e.g. TB), bone marrow involvement, extranodal spread and poor general health.

The 2-year OS rate for our 37 patients with HIV-associated BL was $41 \%$, which is lower than that reported by American study in whom 34 patients survived (69\%)..$^{53}$ This is difficult to compare with international studies because of lack of data on CD4 counts, antiretroviral (ARV) therapies and HIV viral load in our study. Our study included six children with $\mathrm{HIV}$-associated $\mathrm{BL}$, who received intensive chemotherapy. No statistically significant difference was observed amongst children in relation to HIV status and outcome ( $p=0.899)$. There are few case reports of children with immunodeficiencyassociated BL in the world. ${ }^{54,55,56}$

The sample size of HIV-negative adults $(n=4)$ could not be reliably analysed and additional research is required. An international study of 52 immunocompetent adults with BL showed an event-free survival rate of $65 \%$ at 2 years. ${ }^{27,52}$ One European study included 13 patients with immunodeficiency-associated Burkitt's lymphoma, who are reported to have a worse outcome than those with other variants of the disease. ${ }^{57}$ Human immunodeficiency virus-positive patients (on ART and virally suppressed) are seen to have similar outcomes to their HIV-negative counterparts as well as the fact that the use of ART with chemotherapy may be associated with a favourable outcome. The study also noted that the administration of ART was not associated with any significant increase in toxicity. ${ }^{57}$ The authors concluded that hyper-CVAD was highly effective within this context. 
One quarter of patients (25\%) demised before the initiation of chemotherapy (early deaths) because of disease-related complications and/or associated co-morbidities. Factors that may have delayed the initiation of chemotherapy in adults include late presentation with advanced disease, poor general condition, spontaneous tumour lysis, renal impairment and complications of HIV infection. Sepsis was the cause of death in $80 \%$ of children, whilst both sepsis and disease progression were the cause of death in $39 \%$ of adults, suggesting that good outcomes may still be achieved in the resource-limited settings. This remains a serious concern in HIV-positive patients and other frail patients who are more prone to infectious complications. ${ }^{42}$

This retrospective study of children and adults with BL showed a 2-year OS of $45.1 \%$ with a better survival for children $(69 \%)$ than adults $(34 \%)(p=0.022)$. Our study showed that paediatric group had an outcome comparable to GFAOP study (overall survival: $69 \%$ vs $61 \%$ ), importantly both studies used similar treatment protocol (LMB protocol). ${ }^{35,45}$ More than one-third $(n=13)$ of our adult group were treated with adapted paediatric LMB protocol, four patients achieved a 2-year survival; this was lower than the study of an adapted paediatric LMB protocol which showed an event-free survival rate of $65 \%$ at 2 years amongst 72 adults with BL. ${ }^{19}$ Hyper-CVAD group $(n=11)$ showed $36 \%$ overall outcome; these findings are in contrast with a similar study conducted by Thomas et al. in which hyper-CVAD alone showed $53 \%$ OS, whilst hyper-CVAD plus rituximab was reported at $86 \%$ OS. ${ }^{58}$

It is important to note that none of our treatment regimens included rituximab, which was not available because of cost constraints. Some studies suggested that addition of rituximab to standard regimens for BL improves survival. ${ }^{4,5,59}$ The cost associated with rituximab makes this approach challenging in LMICs.

Treatment of AIDS-related malignant lymphoma remains a therapeutic challenge, and no data exist on patients with HRL suffering from active opportunistic infections. ${ }^{57}$ South Africa has the highest number of reported multi-drugresistant TB cases globally. ${ }^{39}$ The burden of disease in South Africa because of HIV and TB is high, and these diseases present with similar clinical features as BL. In our study, patients with comorbid TB had the poorest outcome. Therefore, a larger cohort is required to determine the significance of these findings.

Major limitations to our study remain a small sample size and the retrospective nature of the study as well as unavailable data.

\section{Conclusion}

In summary, our study demonstrates better cure rates for BL in children than adults, irrespective of HIV status, with statistical significance $(p=0.022)$. Of note, all children were treated with a single protocol. This is difficult to do in adults because of the varying presentations and co-morbidities in the adult group, and thus, therapy needs to be stratified to avoid undue toxicity.

\section{Acknowledgements}

The authors thank Tygerberg Lymphoma Study Group (TLSG); South African Children Cancer Study Group (SACCSG) Tumour Registry; Faculty of Division of Haematopathology, Division of Clinical Haematology, Clinical Unit of Paediatric Oncology; National Health Laboratory Services; and Tygerberg Hospital (TBH).

\section{Competing interests}

The authors have declared that no competing interest exists.

\section{Authors' contributions}

All authors contributed equally to this work.

\section{Funding information}

This research received no specific grant from any funding agency in the public, commercial or not-for-profit sectors.

\section{Data availability statement}

Data sharing is not applicable to this article as no new data were created or analysed in this study.

\section{Disclaimer}

The views and opinions expressed in this article are those of the authors and do not necessarily reflect the official policy or position of any affiliated agency of the authors.

\section{References}

1. Burkitt D. A sarcoma involving the jaws in African children. $\mathrm{Br} J$ Surg. 1958;46(197):218-223. https://doi.org/10.1002/bjs.18004619704

2. Song JY, Venkataraman $G$, Fedoriw $Y$, et al. Burkitt leukemia limited to the bone marrow has a better prognosis than Burkitt lymphoma with bone marrow involvement in adults. Leuk Lymphoma. 2016;57(4):866-871. https://doi.org/10. 3109/10428194.2015.1085529

3. Gupta R, Yadav JS, Yadav S, et al. Orbital involvement in nonendemic Burkitt's lymphoma. Orbit. 2012;31(6):441-445. https://doi.org/10.3109/01676830.2012. 711886

4. Barnes JA, Lacasce AS, Feng $Y$, et al. Evaluation of the addition of rituximab to CODOX-M/IVAC for Burkitt's lymphoma: A retrospective analysis. Ann Oncol. CODOX-M/IVAC for Burkitt's lymphoma: A retrospective analysis.
2011;22(8):1859-1864. https://doi.org/10.1093/annonc/mdq677

5. Wildes MT, Farrington L, Yeung $C$, et al. Rituximab is associated with improved survival in Burkitt lymphoma: A retrospective analysis from two US academic medical centers. Ther Adv Hematol. 2014;5(1):3-12. https://doi.org/10. 1177/2040620713514682

6. Aldoss IT, Weisenburger D, Fu K, et al. Adult Burkitt lymphoma: Advances in diagnosis and treatment. Oncology. 2008;22(13):1508-1517.

7. Ferry JA. Burkitt's lymphoma: Clinicopathologic features and differential diagnosis. Oncologist. 2006;11(4):375-383. https://doi.org/10.1634/theoncologist.11-4-375

8. Banks PM, Gralnick HR, Arseneau JC, et al. American Burkitt's lymphoma: A clinicopathologic study of 30 cases. Am J Med. 1975;58(3):314-321. https://doi. org/10.1016/0002-9343(75)90597-5

9. Kemeny M, Magrath T, Brennanh MF. The role of surgery in the management of American Burkitt's lymphoma and its treatment, American Burkitt's lymphoma. Ann Surg. 1982;196(I):82-86. https://doi.org/10.1097/00000658-19820700000017

10. Blum KA, Lozanski G, Byrd JC. Adult Burkitt leukemia and lymphoma. Blood. 2004;104(10):3009-3020. https://doi.org/10.1182/blood-2004-02-0405 
11. Leoncini L. Burkitt lymphoma. In: Swerdlow SH, Campo E, Harris NL, et al., editors. WHO classification of tumours of haematopoetic and lymphoid tissues. 4th ed. Lyon: International Agency for Research on Cancer (IARC), 2008; pp. 262-264.

12. Evans AG, Friedberg JW. Burkitt lymphoma, In: Kaushansky K, Lichtman MA Prchal JT, et al., editors. Williams haematology. 9th ed. New York: McGraw-Hill Education/Medical Publishing, 2015; Chapter 102, p. 1671.

13. Straathof KCM, Bollard CM, Rooney CM, et al. Immunotherapy for Epstein-Bar virus-associated cancers in children. Oncologist. 2003;8(1):83-98. https://doi org/10.1634/theoncologist.8-1-83

14. Cai Q, Medeiros JL, Xu X, et al. MYC-driven aggressive B-cell lymphomas: Biology, entity, differential diagnosis and clinical management. 2015;6(36):38591-38616. https://doi.org/10.18632/oncotarget.5774

15. Salaverria I, Martin-Guerrero I, Wegener R, et al. A recurrent 11q aberration pattern characterizes a subset of MYC-negative high-grade B-cell lymphomas resembling Burkitt lymphoma. Blood. 2014;123(8):1187-1198. https://doi. org/10.1182/blood-2013-06-507996

16. Diebold J. Burkitt lymphoma. In: Jaffe ES, Harris NL, Stein H, Vardiman JW, editors WHO classification of tumours of haematopoetic and lymphoid tissues. 3rd ed. Lyon: IARC Press, 2001; pp. 181-184.

17. Ostronoff $M$, Soussain C, Zambon E, et al. Burkitt's lymphoma in adults: A retrospective study of 46 cases. Nouv Rev Fr Hematol. 1992;34:389-397.

18. McClenathan JH. Burkitt's lymphoma of the abdomen: The Northern California Kaiser permanente experience. Internet J Surg. 2008;18(2):1-5. https://doi. org $/ 10.5580 / 165 f$

19. Patte $C$, Auperin A, Gerrard M, et al. Results of the randomized international FAB/ LMB96 trial for intermediate risk B-cell non-Hodgkin lymphoma in children and adolescents: It is possible to reduce treatment for the early responding patients. Blood. 2007;109(7):2773-2780. https://doi.org/10.1182/blood-2006-07-036673

20. Intermesoli T, Rambaldi A. High cure rates in Burkitt lymphoma and leukemia: A Northern Italy leukemia group study of the German short intensive rituximabchemotherapy program. Haematologica. 2013;98(11):1718-1725. https://doi. org/10.3324/haematol.2013.086827

21. Lewis N, Young J, Hesseling PB, McCormick P, Wright N. Epidemiology of Burkitt's lymphoma in Northwest Province, Cameroon, 2003-2010. Paediatr Int Child Health. 2012;32(2):82-85.

22. Gerrard M, Cairo MS, Weston C, et al. Excellent survival following two courses of COPAD chemotherapy in children and adolescents with resected localized B-cell nonHodgkin's lymphoma: Results of the FAB/LMB 96 international study. Br J Haematol. 2008;141(6):840-847. https://doi.org/10.1111/j.1365-2141.2008.07144.x

23. Mead GM, Sydes MR, Walewski J, et al. An international evaluation of CODOX-M and CODOX-M alternating with IVAC in adult Burkitt's lymphoma: Results of United Kingdom Lymphoma Group LY06 study. Ann Oncol. 2002;13(8):1264-1274. https://doi.org/10.1093/annonc/mdf253

24. Diviné $M$, Casassus $P$, Koscielny $S$, et al. Burkitt lymphoma in adults: A prospective study of 72 patients treated with an adapted pediatric LMB protocol. Ann Oncol. 2005;16(12):1928-1935. https://doi.org/10.1093/annonc/mdi403

25. Hoelzer D, Walewski J, Döhner H, et al. Improved outcome of adult Burkitt lymphoma/leukemia with rituximab and chemotherapy: Report of a large prospective multicenter trial. Blood. 2014;124(26):3870-3879. https://doi. org/10.1182/blood-2014-03-563627

26. Hesseling P, Molyneux E, Tchintseme F, et al. 0.095 Oral cyclophosphamide (cpm) and intrathecal methotrexate (IT MTX) 140 children with Burkitt lymphoma. Pediatr Blood Cancer. 2006;47:381. (abstract).

27. Kim H, Park ES, Lee $\mathrm{SH}$, et al. Clinical outcome of relapsed or refractory burkitt lymphoma and mature B-cell lymphoblastic leukemia in children and adolescents. Cancer Res Treat. 2014;46(4):358-365. https://doi.org/10.4143/ crt.2013.047

28. Griffin TC, Weitzman $\mathrm{S}$, Weinstein $\mathrm{H}$, et al. A study of rituximab and ifosfamide, carboplatin and etoposide chemotherapy in children with recurrent/refractory $\mathrm{B}$-cell $\left(\mathrm{CD} 2 \mathrm{O}^{+}\right)$non-Hodgkin lymphoma and mature B-cell acute lymphoblastic leukemia: A report from the children's oncology group. Pediatr Blood Cancer. 2009;52(2):177-181. https://doi.org/10.1002/pbc.21753

29. Van den Hof S, Collins D, Hafidz F, et al. The socioeconomic impact of multidrug resistant tuberculosis on patients: Results from Ethiopia, Indonesia and Kazakhstan. BMC Infect Dis. 2016;16:470. https://doi.org/10.1186/s12879-016$1802-x$

30. Peddireddy V. Quality of life, psychological interventions and treatment outcome in tuberculosis patients: The Indian Scenario. Front Psychol. 2016;7(12):3067. https://doi.org/10.3389/fpsyg.2016.01664

31. Fantom N, Serajuddin U. Policy research working paper 7528. The World Bank's classification of countries by income [homepage on the Internet]. Data Group, Development Economics. World Bank; c2016 [cited 1 Apr 2020]. Available from: https://econ.worldbank.org

32. Meintjes G, Moorhouse MA, Carmano S, et al. Adult antiretroviral therapy guidelines 2017. S Afr J HIV Med. 2017;18(1):a776. https://doi.org/10.4102/ sajhivmed.v18i1.776

33. Groenewald P, Msemburi W, Morden E, et al. Western Cape mortality profile 2011. Cape Town: South African Medical Research Council; 2014

34. Pagano L, Caira M, Valentini CG, et al. Clinical aspects and therapy of sporadic Burkitt lymphoma. Meditrr J Hematol Infect Dis. 2009;1(2):e2009030. https://doi. org/10.4084/MJHID.2009.030
35. Saletta F, Seng MS, Lau LMS, et al. Advances in paediatric cancer treatment. Transl Pediatr. 2014;3(2):156-182

36. Thomas DA, Cortes J, O'Brien S, et al. Hyper-CVAD program in Burkitt's-type adult acute lymphoblastic leukemia. J Clin Oncol. 1999;17(8):2461-2470. https://doi. org/10.1200/JCO.1999.17.8.2461

37. Jerkeman $M$, Anderson $H$, Cavallin-Ståhl $E$, et al. CHOP versus MACOP-B in aggressive lymphoma: A Nordic Lymphoma Group randomised trial. Ann Oncol. 1999;10(9):1079-1086. https://doi.org/10.1023/A:1008392528248

38. Saito H, Mizoguchi H. Treatment of elderly patients with hematological malignancies. Gan To Kagaku Ryoho. 1992;19(11):1801-1807.

39. National Department of Health. Joint review of HIV, TB and PMCT programmes in South Africa. Pretoria: Department of Health; 2014.

40. Abayomi EA, Somers A, Grewal R, et al. Impact of the HIV epidemic and antiretroviral treatment policy on lymphoma incidence and subtypes seen in the Western Cape of South Africa, 2002-2009: Preliminary findings of the Tygerberg Lymphoma Study Group. Transfus Apher Sci. 2011;44(2):161-166. https://doi. org/10.1016/j.transci.2011.01.007

41. Stefans DC, Stone DK, Wainwrigh D, et al. Childhood cancer incidence in South Africa, 1987-2007. S Afr Med J. 2015;105(11):939-947. https://doi.org/10.7196/ SAMJ.2015.v105i11.9780

42. Dozzo M, Carobolante F, Donisi PM, et al. Burkitt lymphoma in adolescents and young adults: Management challenges. Adolesc Health Med Ther. 2017;8:11-29. https://doi.org/10.2147/AHMT.S94170

43. Georgakis MK, Karalexi M, Agius D, et al. Incidence and time trends of childhood lymphomas: Findings from 14 Southern and Eastern European cancer registries and the surveillance, epidemiology and end results, USA. Cance Causes Control. 2016;27(11):1381-1395. https://doi.org/10.1007/s10552-0160817-3

44. Rendón-Macías EM, Valencia-Ramón AE, Fajardo-Gutiérrez A. Clinical and epidemiological characteristics of Burkitt lymphomas in pediatric patients from two defined socioeconomic regions in Mexico. J Trop Pediatr. 2017; 63(4):253-259.

45. Béogo R, Nacro B, Ouédraogo D, et al. Endemic Burkitt lymphoma of maxillofacial region: Results of induction treatment with cyclophosphamide plus methotrexate in West Africa. Pediatr Blood Cancer. 2011;56(7):1068-1070. https://doi. org/10.1002/pbc. 23058

46. Shisana O, Rehle T, Simbayi LC, et al. South African national HIV prevalence, incidence and behaviour survey, 2012. Cape Town: HSRC Press; 2014.

47. Mantina H, Wiggill TM, Carmona S, et al. Characterization of lymphomas in a high prevalence HIV setting. J Acquir Immune Defic Syndr. 2010;53(5):656-660. https://doi.org/10.1097/QAl.0b013e3181bf5544

48. Wiggill TM, Mantina $H$, Willem $P$, et al. Changing pattern of lymphoma subgroups at a tertiary academic complex in a high-prevalence HIV setting: A South African perspective. J Acquir Immune Defic Syndr. 2011;56(5):460-466. https://doi. perspective. J Acquir Immune Defic
org/10.1097/QAl.0b013e31820bb06a

49. Basavaraj A, Shinde A, Kulkarni R, et al. HIV associated Burkitt's lymphoma. J Assoc Physicians India. 2014;62(8):723-727.

50. Costa $L$, Xavier AC, Wahlquist $A E$, et al. Trends in survival of patients with Burkitt lymphoma/leukemia in the USA: An analysis of 3691 cases. Blood. 2013; 121(24):4861-4866. https://doi.org/10.1182/blood-2012-12-475558

51. Cunha KCCMS, Oliveira MCLA, Gomes ACSG, et al. Clinical course and prognostic factors of children with Burkitt's lymphoma in a developing country: The experience of a single centre in Brazil. Rev Bras Hematol Hemoter. 2012 34(5):361-366. https://doi.org/10.5581/1516-8484.20120093

52. Dunleavy K, Pittaluga S, Shovin M, et al. Low-intensity therapy in adults with Burkitt's lymphoma. N Engl J Med. 2013;369(20):1915-1925. https://doi. org/10.1056/NEJMoa1308392

53. Rodrigo JA, Hicks LK, Cheung MC, et al. HIV-Associated Burkitt lymphoma: Good efficacy and tolerance of intensive chemotherapy including CODOX-M/IVAC with or without rituximab in the HAART era. Adv Hematol. 2012;2012(21):735392. https://doi.org/10.1155/2012/735392

54. Huang S, Suhrland MJ, Gritz D. Recurrent immunodeficiency-associated Burkitt lymphoma presenting as severe anterior uveitis. Ocul Oncol Pathol. 2015;2(2):62-65. https://doi.org/10.1159/000439054

55. Choudhary Z, Gupta P, Kumar MU. Burkitt's lymphoma in HIV- positive child: Diagnostic ascitic fluid cytology. J Clin Diagn Res. 2017;11(1):EL01-EL02. https:// Diagnostic ascitic fluid cytology. J Clin Diagn
doi.org/10.7860/JCDR/2017/24425.9137

56. Urbano S, López E, Harris J. Immunodeficiency-associated Burkitt's lymphoma in pediatric patients: A clinical case report. J Oral Res. 2018;7(4):141-144. https:// doi.org/10.17126/joralres.2018.034

57. Cortes J, Thomas D, Rios A, et al. Hyperfractionated cyclophosphamide, vincristine, doxorubicin, and dexamethasone and highly active antiretrovira therapy for patients with acquired immunodeficiency syndrome-related Burkitt lymphoma/leukemia. Cancer. 2002;94(5):1492-1499. https://doi.org/10.1002/ cncr.10365

58. Thomas DA, Kantarjian HM, Cortes J, et al. Long-term outcome after HyperCVAD and rituximab chemoimmunotherapy for Burkitt (BL) or Burkittlike (BLL) leukemia/lymphoma and mature B-cell acute lymphocytic leukemia (ALL). Blood. 2008;112:1929. https://doi.org/10.1182/blood. leukemia (ALL).

59. Wasterlid T, Brown PN, Hagberg O, et al. Impact of chemotherapy regimen and rituximab in adult Burkitt lymphoma: A retrospective population-based study from the Nordic Lymphoma Group. Ann Oncol. 2013;24(7):1879-1886. 